\title{
HUBUNGAN ANTARA PENGALAMAN PRAKTIK KERJA INDUSTRI DAN EFIKASI DIRI DENGAN KESIAPAN KERJA SISWA KELAS XII SMK NEGERI 55 JAKARTA TAHUN 2019 \\ ${ }^{1}$ Karina Febrianti, ${ }^{2}$ Faried Wadjdi, ${ }^{3}$ Irzan Zakir \\ ${ }^{123}$ Pendidikan Teknik Elektro, Fakultas Teknik, Universitas Negeri Jakarta \\ ${ }^{123}$ Email: karinaafebrianti@yahoo.com ; faried@unj.ac.id ; irzan.zakir@unj.ac.id
}

\begin{abstract}
This research aimed to know correlation between industrial work experiences and readiness on SMK students to work, correlation between self-efficacy and readiness on SMK students to work, correlation between industrial work experiences and self-efficacy, and also to know correlation between industrial work experiences and self-efficacy simultaneously on readiness of the students of grades XII in SMKN 55 Jakarta to work. This research is a type of descriptive quantitative research with ex-post facto method. The sample in this study amounted to 64 students taken with purposive sampling. Method of collecting data in the form of questionnaires. The data analyzed using product moment correlation. The result showed that there was a positive and significant correlation between industrial work experiences and readiness on SMK students to work that proven by the $r_{\text {count }}>r_{\text {table }}$ $(0,664>0,246)$ with coefficients $r=41 \%$, there was a positive and significant correlation between self-efficacy and readiness on SMK students to work that proven by the $r_{\text {count }}>r_{\text {table }}(0,572>0,246)$ with coefficients $r=33 \%$, there was a positive and significant correlation between industrial work experiences and self-efficacy that proven by the $r_{\text {count }}>r_{\text {table }}(0,723>0,246)$ with coefficients $r=$ $52 \%$, there was a positive and significant correlation between industrial work experiences, selfefficacy and readiness on SMK students to work that proven by the $r_{\text {count }}>r_{\text {table }}(0,662>0,246)$ with coefficients $r=44 \%$.
\end{abstract}

Keyword: industrial work experiences, self-efficacy, and readiness of the students to work

\begin{abstract}
Abstrak
Penelitian ini bertujuan untuk mengetahui adanya hubungan antara pengalaman praktik kerja industri dengan kesiapan kerja siswa, hubungan antara efikasi diri dengan kesiapan kerja siswa, hubungan antara pengalaman praktik kerja industri dengan efikasi diri, dan hubungan antara pengalaman praktik kerja industri dan efikasi diri secara simultan dengan kesiapan kerja siswa. Penelitian ini merupakan penelitian ex-post facto menggunakan pendekatan kuantitatif. Sampel penelitian yang digunakan adalah 64 siswa dengan menggunakan teknik purposive sampling. Teknik pengumpulan data dengan menggunakan angket. Teknik analisis yang digunakan adalah korelasi product moment. Kesimpulan dari penelitian ini adalah terdapat hubungan yang positif dan signifikan antara pengalaman praktik kerja industri dengan kesiapan kerja siswa yang dibuktikan dengan nilai $r_{\text {hitung }}>$ dari $\mathrm{r}_{\text {tabel }}(0,664>0,246)$ dengan koefisien determinasi sebesar $41 \%$, terdapat hubungan yang positif dan signifikan antara efikasi diri dengan kesiapan kerja siswa yang dibuktikan dengan nilai $\mathrm{r}_{\text {hitung }}>$ $\mathrm{r}_{\text {tabel }}(0,572>0,246)$ dengan koefisien determinasi sebesar 33\%, terdapat hubungan yang positif dan signifikan antara pengalaman praktik kerja industri dengan efikasi diri yang dibuktikan dengan nilai $\mathrm{r}_{\text {hitung }}>\mathrm{r}_{\text {tabel }}(0,723>0,246)$ dengan koefisien determinasi sebesar $52 \%$, terdapat hubungan yang positif dan signifikan antara pengalaman praktik kerja industri dan efikasi diri dengan kesiapan kerja siswa yang dibuktikan dengan nilai $r_{\text {hitung }}>r_{\text {tabel }}(0,662>0,246)$ dengan koefisien determinasi sebesar $44 \%$.
\end{abstract}

Kata kunci: Pengalaman praktik kerja industri, efikasi diri, dan kesiapan kerja siswa

\section{PENDAHULUAN}

Program pembelajaran dalam Sekolah Menengah Kejuruan (SMK) menggunakan kurikulum yang menitikberatkan pada aspek keterampilan praktis dan fungsional yang meliputi aspek teori maupun pembekalan keterampilan khusus untuk mempersiapkan lulusan SMK yang mampu bersaing menghadapi persaingan dunia kerja. Agar dapat bersaing di dunia kerja maka siswa SMK diharapkan mempunyai kemampuan kesiapan kerja siswa sesuai dengan kompetensi yang dimiliki. Kesiapan kerja siswa adalah kemampuan yang dimiliki siswa yang 
meliputi kesiapan psikis dan fisik, efikasi diri, serta pengalaman kerja yang dimiliki. Kesiapan kerja dipengaruhi beberapa faktor internal maupun faktor eksternal. Faktor internal yang mempengaruhi kesiapan kerja siswa adalah kondisi fisik dan psikis, kemampuan berkomunikasi, dan efikasi diri. ${ }^{[1]}$ Menurut Hudaniyah (2013:3) siswa yang mampu mengenal kemampuan diri dan memiliki kepercayaan diri yang tinggi akan merasa yakin dan siap untuk mendapatkan pekerjaan. ${ }^{[2]} \mathrm{Hal}$ tersebut sejalan dengan penelitian yang dikutip pada jurnal yang ditulis oleh Syafiq (2013) bahwa terdapat hubungan yang positif dan signifikan antara efikasi diri dengan kesiapan kerja siswa. Sedangkan faktor eksternal yang mempengaruhi kesiapan kerja siswa adalah pengalaman kerja yang bisa didapatkan dari kegiatan praktik kerja industri. ${ }^{[3]}$ Berdasarkan penelitian yang dilakukan oleh Sirsa (2014) menyimpulkan kesiapan kerja siswa sangat dipengaruhi secara parsial oleh pengalaman praktik kerja industri. ${ }^{[4]}$ Selanjutnya dalam pelaksanaan praktik kerja industri, pedoman pembinaan dan pengembangan Sekolah Menengah Kejuruan untuk menyiapkan tenaga kerja industri yang terampil dan berkompeten maka diperlukan pendidikan kejuruan yang berbasis kompetensi yang link and match dengan industri telah ditegaskan oleh Dikmenjur (2013: 10) bahwa penyelenggaraan praktik kerja industri diharapkan akan membantu siswa untuk memantapkan hasil belajar yang telah diperoleh selama belajar formal disekolah dan membekali siswa agar memperoleh pengalaman kerja langsung secara nyata sesuai dengan program studi yang dipilihnya, untuk mencetak calon tenaga kerja yang berkualitas yang memiliki pengetahuan dan keterampilan yang baik, memperoleh kompetensi yang link and match antara pihak sekolah dengan industri, serta memberikan pelatihan kerja yang berkualitas guna mengembangkan kompetensi keahlian yang dimiliki siswa.
Praktik kerja industri juga diharapkan dapat menjadi fasilitas siswa agar dapat menyesuaikan diri dengan lingkungan kerja dan dapat mengimplementasikan ilmu yang dimiliki sebelumnya agar mendapatkan hasil yang baik.

Namun dalam pelaksanaannya, praktik kerja industri yang diselenggarakan oleh SMK masih menghadapi beberapa kendala. Kendala tersebut diantaranya pengalaman yang didapatkan siswa dari praktik kerja industri masih minim. Hal ini disebabkan oleh kurangnya komunikasi antara praktikan dengan karyawan industri. Pihak industri masih menilai kemampuan siswa SMK kurang berkompeten dan belum memiliki kesiapan dalam bekerja. Siswa dinilai kurang mampu dalam menerapkan keterampilan dan pengetahuan yang didapatlan di sekolah karena siswa tidak terbiasa dengan peralatan-peralatan yang ada di industri yang jarang ditemui siswa di sekolah. Kendala-kendala yang ditemukan saat melakukan praktik kerja industri ini membuat siswa kurang percaya diri terhadap kemampuan yang dimilikinya dalam melakukan praktik kerja industri. Berdasarkan observasi awal yang dilakukan peneliti di SMK Negeri 55 Jakarta dengan melakukan komunikasi bersama pihak guru produktif dan wakil kurikulum SMK Negeri 55 Jakarta diketahui bahwa kesiapan kerja siswa di sekolah tersebut masih tergolong minim. Hal ini diperkuat dengan data penelitian yang menunjukkan bahwa siswa SMK Negeri 55 Jakarta memiliki kesiapan kerja yang rendah dikarenakan beberapa faktor diantaranya fasilitas penunjang kesiapan kerja seperti alat-alat industri yang ada di sekolah kurang lengkap dan aktual sehingga ketika siswa melakukan kegiatan praktik kerja industri belum familiar dengan alat-alat yang ada di industri.

\section{METODE PENELITIAN}

Jenis desain penelitian ini termasuk dalam penelitian deskriptif korelatif. 
${ }^{[5]}$ penelitian ini menggunakan pendekatan kuantitatif, dimana menurut Sugiyono (2012) pendekatan kuantitatif adalah pendekatan dengan pengumpulan data menggunakan instrument penelitian yang bersifat analisis kuantitatif/statistik dengan tujuan menguji hipotesis yang telah ditetapkan. Penelitian ini ditunjukkan untuk menguji hipotesis yang telah ditetapkan dengan cara mencari hubungan variabel bebas dengan variabel terikat. Paradigm atau model hubungan antara variabel X1, X2, dan Y dapat dilihat pada.

Populasi dalam penelitian ini adalah siswa kelas XII program kejuruan Teknik Instalasi Tenaga Listrik di SMK Negeri 55 Jakarta sebanyak 64 siswa. Teknik sampling yang digunakan adalah teknik porposive sampling. ${ }^{[6]}$ Menurut Sugiyono (2016) teknik purposive sampling adalah teknik penentuan sampel dengan pertimbangan kriteria tertentu. Teknik pengumpulan data untuk variabel pengalaman praktik kerja industri, efikasi diri, dan kesiapan kerja menggunakan kuesioner (angket). Instrumen penelitian menggunakan uji validitas dengan rumus korelasi Pearson's Product Moment. Pengujian reliablitas pada instrumen kuesioner menggunakan koefisien reliabilitas Alfa Cronbach. Teknik analisis data yang digunakan dalam penelitian ini adalah statistik deskriptif. Pengujian hipotesis dalam penelitian ini menggunakan nilai $\alpha=0,05$, namun sebelum melakukan uji hipotesis, terlebih dahulu dilakukan uji normalitas menggunakan Chi Kuadrat dan linearitas. Lalu setelah melakukan uji normalitas dan uji lilearitas maka dilakukan uji hipotesis menggunakan analisis korelasi Pearson's Product Moment dan melakukan uji signifikansi pada variabel menggunakan uji-t dan uji-F.

\section{HASIL DAN PEMBAHASAN \\ Kesiapan Kerja Siswa}

Hasil analisis deskriptif terhadap data hasil penelitian, diperoleh nilai rata-rata sebesar 110,3438, nilai modus sebesar
110,59, dan nilai median sebesar 110,25. Tabel distribusi frekuensi skor kesiapan kerja siswa seperti pada tabel 1.

\section{Tabel 1 Distribusi Frekuensi Kesiapan}

\section{Kerja Siswa}

\begin{tabular}{cclcc}
\hline No. & $\begin{array}{c}\text { Interval } \\
\text { kelas }\end{array}$ & Batas kelas & $(\mathrm{Fi})$ & $(\mathrm{Fr})$ \\
\hline 1 & $92-97$ & $\begin{array}{l}91.5-97.5 \\
97.5-\end{array}$ & 6 & $9 \%$ \\
2 & $98-103$ & $\begin{array}{l}97.5 \\
103.5\end{array}$ & $17 \%$ \\
3 & $104-109$ & $\begin{array}{l}103.5- \\
09.5\end{array}$ & 13 & $20 \%$ \\
4 & $110-115$ & $\begin{array}{l}109.5- \\
15.5\end{array}$ & 16 & $25 \%$ \\
5 & $116-121$ & $\begin{array}{l}115.5- \\
21.5\end{array}$ & 10 & $16 \%$ \\
6 & $122-127$ & $\begin{array}{l}121.5- \\
27.5\end{array}$ & 4 & $6 \%$ \\
7 & $128-133$ & $\begin{array}{l}127.5- \\
33.5\end{array}$ & 4 & $6 \%$ \\
\hline \multicolumn{5}{c}{ Jumlah } \\
\hline
\end{tabular}

Berdasarkan tabel 1 distribusi frekuensi dapat diketahui bahwa variabel kesiapan kerja siswa memiliki frekuensi tertinggi yaitu pada kelas interval 110-115 dengan frekuensi sebesar 16 siswa dan memiliki frekuensi relatif sebesar $25 \%$ dari total sampel. Sedangkan frekuensi terendah yaitu pada kelas interval 122-127 dan interval 128-133 dengan frekuensi sebesar 4 dan memiliki frekuensi relatif sebesar $6 \%$ dari total sampel. Kemudian hasil lainnya yaitu sebanyak 6 siswa memiliki nilai rentang antara 92-97 dengan frekuensi relatif sebesar $9 \%$ dari total sampel, 11 siswa memiliki nilai rentang antara 98-103 dengan frekuensi relatif sebesar $17 \%$ dari total sampel, 13 siswa memiliki nilai rentang antara 104-109 dengan frekuensi relatif sebesar $20 \%$ dari total sampel, dan 10 siswa memiliki nilai rentang antara 116-121 dengan frekuensi relatif sebesar $16 \%$ dari total sampel.

\section{Pengalaman Praktik Kerja Industri}

Hasil analisis deskriptif terhadap data hasil penelitian, diperoleh nilai rata-rata sebesar 116,0781, nilai modus sebesar 113,125 , dan nilai median sebesar 114,70. 
Tabel distribusi frekuensi skor pengalaman praktik kerja industri seperti pada tabel 2.

Tabel 1 Distribusi Frekuensi Pengalaman Praktik Kerja Industri

\begin{tabular}{|c|c|c|c|c|}
\hline No. & $\begin{array}{c}\text { Interval } \\
\text { kelas }\end{array}$ & $\begin{array}{l}\text { Batas } \\
\text { kelas }\end{array}$ & $(\mathrm{Fi})$ & (Fr) \\
\hline 1 & $90-96$ & $\begin{array}{c}89.5- \\
96.5\end{array}$ & 2 & $3 \%$ \\
\hline 2 & $97-103$ & $\begin{array}{l}96.5- \\
103.5\end{array}$ & 4 & $6 \%$ \\
\hline 3 & $104-110$ & $\begin{array}{c}103.5- \\
110.5\end{array}$ & 14 & $22 \%$ \\
\hline 4 & $111-117$ & $\begin{array}{c}110.5- \\
117.5\end{array}$ & 20 & $31 \%$ \\
\hline 5 & $118-124$ & $\begin{array}{c}117.5- \\
124.5\end{array}$ & 10 & $16 \%$ \\
\hline 6 & $125-131$ & $\begin{array}{c}124.5- \\
131.5\end{array}$ & 5 & $8 \%$ \\
\hline 7 & $132-138$ & $\begin{array}{c}131.5- \\
138.5\end{array}$ & 9 & $14 \%$ \\
\hline \multicolumn{3}{|c|}{ Jumlah } & 64 & $100 \%$ \\
\hline
\end{tabular}

Berdasarkan tabel 2 distribusi frekuensi dapat diketahui bahwa variabel pengalaman praktik kerja industri memiliki frekuensi tertinggi yaitu pada kelas interval 111-117 dengan frekuensi sebesar 20 siswa dan memiliki frekuensi relatif sebesar $31 \%$ dari total sampel. Sedangkan frekuensi terendah yaitu pada kelas interval 90-96 dengan frekuensi sebesar 2 dan memiliki frekuensi relatif sebesar 3\% dari total sampel. Kemudian hasil lainnya yaitu sebanyak 4 siswa memiliki nilai rentang antara 97-103 dengan frekuensi relatif sebesar $6 \%$ dari total sampel, 14 siswa memiliki nilai rentang antara 104110 dengan frekuensi relatif sebesar 22\% dari total sampel, 10 siswa memiliki nilai rentang antara 118-124 dengan frekuensi relatif sebesar $16 \%$ dari total sampel, 5 siswa memiliki nilai rentang antara 125131 dengan frekuensi relatif sebesar $8 \%$ dari total sampel, dan 9 siswa memiliki nilai rentang antara 132-138 dengan frekuensi relatif sebesar $14 \%$ dari total sampel.

\section{Efikasi Diri}

Hasil analisis deskriptif terhadap data hasil penelitian, diperoleh nilai rata-rata sebesar 99,0156, nilai modus sebesar 101,214, dan nilai median sebesar 99,346. Tabel distribusi frekuensi skor efikasi diri seperti pada tabel 3.

Tabel 3 Distribusi Frekuensi Efikasi Diri

\begin{tabular}{|c|c|c|c|c|}
\hline No. & $\begin{array}{c}\text { Interval } \\
\text { kelas }\end{array}$ & $\begin{array}{l}\text { Batas } \\
\text { kelas }\end{array}$ & (Fi) & (Fr) \\
\hline 1 & $81-85$ & $\begin{array}{c}80.5- \\
85.5\end{array}$ & 4 & $6 \%$ \\
\hline 2 & $86-90$ & $\begin{array}{c}85.8- \\
90.5\end{array}$ & 8 & $13 \%$ \\
\hline 3 & $91-95$ & $\begin{array}{c}90.5- \\
95.5\end{array}$ & 10 & $16 \%$ \\
\hline 4 & $96-100$ & $\begin{array}{c}95.5- \\
100.5\end{array}$ & 13 & $20 \%$ \\
\hline 5 & $101-105$ & $\begin{array}{c}100.5- \\
105.5\end{array}$ & 14 & $22 \%$ \\
\hline 6 & $106-110$ & $\begin{array}{c}105.5- \\
110.5\end{array}$ & 8 & $13 \%$ \\
\hline 7 & $111-115$ & $\begin{array}{c}110.5- \\
115.5 \\
\end{array}$ & 7 & $11 \%$ \\
\hline & Jumla & & 64 & $100 \%$ \\
\hline
\end{tabular}

Berdasarkan tabel 3 distribusi frekuensi dapat diketahui bahwa variabel efikasi diri memiliki frekuensi tertinggi yaitu pada kelas interval 101-105 dengan frekuensi sebesar 14 siswa dan memiliki frekuensi relatif sebesar $22 \%$ dari total sampel. Sedangkan frekuensi terendah yaitu pada kelas interval 81-95 dengan frekuensi sebesar 4 dan memiliki frekuensi relatif sebesar $6 \%$ dari total sampel. Kemudian hasil lainnya yaitu sebanyak 8 siswa memiliki nilai rentang antara 86-90 dengan frekuensi relatif sebesar $13 \%$ dari total sampel, 10 siswa memiliki nilai rentang antara 91-95 dengan frekuensi relatif sebesar $16 \%$ dari total sampel, 13 siswa memiliki nilai rentang antara 96-100 dengan frekuensi relatif sebesar $20 \%$ dari total sampel, 8 siswa memiliki nilai rentang antara 106-110 dengan frekuensi relatif sebesar $13 \%$ dari total sampel, dan 7 siswa memiliki nilai rentang antara 111115 dengan frekuensi relatif sebesar $11 \%$ dari total sampel. 


\section{Pengujian Persyaratan Analisis Data Uji Normalitas}

Berikut adalah perhitungan uji normalitas pengalaman praktik kerja industri, efikasi diri, dan kesiapan kerja yang dapat dilihat pada tabel 4

Tabel 4. Uji Normalitas Pengalaman Praktik Kerja Industri, Efikasi Diri dan Kesiapan Kerja

\begin{tabular}{ccccc}
\hline $\begin{array}{c}\text { Uji } \\
\text { Normalitas }\end{array}$ & Dk & $\begin{array}{c}\chi^{\mathbf{2}} \\
\text { tabel }\end{array}$ & $\begin{array}{c}\chi^{\mathbf{2}} \\
\text { hitung }\end{array}$ & Ket \\
\hline $\begin{array}{c}\text { Pengalaman } \\
\text { Praktik }\end{array}$ & 6 & 12,59 & 12,25 & Normal \\
$\begin{array}{c}\text { Kerja Industri } \\
\text { Efikasi Diri }\end{array}$ & 6 & 12,59 & 3,344 & Normal \\
$\begin{array}{c}\text { Kesiapan } \\
\text { Kerja }\end{array}$ & 6 & 12,59 & 3,384 & Normal \\
\hline
\end{tabular}

Pada tabel 4 pada variabel pengalaman praktik kerja industri $\left(\mathrm{X}_{1}\right)$ diperoleh nilai $\chi$ ${ }^{2}$ hitung sebesar 12,254 sedangkan $\chi^{2}$ tabel sebesar 12,59 untuk $\alpha=0,05$ dan $\mathrm{dk}=6$. Karena $\chi^{2}$ hitung $\leq \chi^{2}{ }_{\text {tabel }}$ maka dapat disimpulkan bahwa penyebaran data pada variabel pengalaman praktik kerja industri berdistribusi normal.

Pada tabel 4 pada variabel efikasi diri $\left(\mathrm{X}_{2}\right)$ diperoleh nilai $\chi^{2}$ hitung sebesar 3,344 sedangkan $\chi^{2}$ tabel sebesar 12,59 untuk $\alpha=$ 0,05 dan $\mathrm{dk}=6$. Karena $\chi^{2}$ hitung $\leq \chi^{2}$ tabel maka dapat disimpulkan bahwa penyebaran data pada variabel efikasi diri berdistribusi normal.

Pada tabel 4 pada variabel Kesiapan Kerja Siswa (Y) diperoleh nilai $\chi^{2}$ hitung sebesar 3,384 sedangkan $\chi^{2}$ tabel sebesar 12,59 untuk $\alpha=0,05$ dan $\mathrm{dk}=6$. Karena $\chi$ ${ }_{\text {hitung }} \leq \chi^{2}$ tabel maka dapat disimpulkan bahwa penyebaran data pada variabel kesiapan kerja siswa berdistribusi normal.

\section{Uji Linieritas}

Berikut adalah perhitungan uji linieritas pengalaman praktik kerja industri dengan kesiapan kerja siswa dan efikasi diri dengan kesiapan kerja siswa dapat dilihat pada tabel 5.

$\begin{array}{ccr}\text { Tabel } & \text { 5. Uji Linieritas } \\ \text { Pengalaman Praktik }\end{array}$

\begin{tabular}{|c|c|c|c|c|}
\hline $\begin{array}{l}\text { Kerja } \\
\text { dengan } \\
\text { Kerja }\end{array}$ & & $\begin{array}{l}\text { Indus } \\
\text { Kesiap }\end{array}$ & & \\
\hline $\begin{array}{c}\text { Uji } \\
\text { Linieritas }\end{array}$ & $\mathbf{n}$ & $\begin{array}{c}\text { F } \\
\text { hitung }\end{array}$ & $\begin{array}{c}F \\
\text { tabel }\end{array}$ & Ket \\
\hline
\end{tabular}

Pengalaman Praktik

Kerja Industri

$$
\text { dengan }
$$

$64 \quad 0,910 \quad 1,84 \quad$ Linier

Kesiapan

Berdasarkan hasil analisis varians (Anava) pada tabel 5 diperoleh nilai $F_{\text {hitung }}$ antara variabel pengalaman praktik kerja industri $\left(\mathrm{X}_{1}\right)$ dan kesiapan kerja siswa $(\mathrm{Y})$ sebesar 0,910 dengan derajat kebebasan (dk) pembilang sebesar $30(\mathrm{dk}=\mathrm{K}-2=32$ $-2=30)$ dan derajat kebebasan (dk) penyebut sebesar $32(\mathrm{dk}=\mathrm{n}-\mathrm{k}=64-32=$ 32) dengan taraf signifikansi $\alpha=5 \%$ diperoleh nilai $F_{\text {tabel }}=1,84$. Dilihat berdasarkan kriteria pengujian yang digunakan, maka diperoleh hasil pengujian hipotesis yang menunjukkan $F_{\text {hitung }}<\mathrm{F}_{\text {tabel }}$ maka $\mathrm{H}_{0}$ diterima sehingga dapat disimpulkan bahwa terdapat hubungan linier antara variabel pengalaman praktik kerja industri dengan kesiapan kerja siswa.

Selanjutnya adalah perhitungan uji linieritas status efikasi diri dengan kesiapan kerja siswa dapat dilihat pada tabel 6.

Tabel 6. Uji Linieritas Efikasi Diri dengan Kesiapan Kerja

\begin{tabular}{ccccc}
$\begin{array}{c}\text { Uji } \\
\text { Linieritas }\end{array}$ & $\mathbf{n}$ & $\begin{array}{c}\mathbf{F} \\
\text { hitung }\end{array}$ & $\begin{array}{c}\mathbf{F} \\
\text { tabel }\end{array}$ & Ket \\
\hline $\begin{array}{c}\text { Efikasi Diri } \\
\text { dengan }\end{array}$ & 64 & 0,685 & 1,84 & Linier \\
$\begin{array}{c}\text { Kesiapan Kerja } \\
\text { Kiaprin }\end{array}$ & & & \\
\hline
\end{tabular}

Berdasarkan hasil analisis varians (Anava) pada tabel 4.13 diperoleh nilai $F_{\text {hitung }}$ antara variabel efikasi diri $\left(\mathrm{X}_{2}\right)$ dan kesiapan kerja siswa (Y) sebesar 0,685 dengan derajat kebebasan (dk) pembilang sebesar $27(\mathrm{dk}=\mathrm{K}-2=29-2=27)$ dan 
derajat kebebasan $(\mathrm{dk})$ penyebut sebesar $35(\mathrm{dk}=\mathrm{n}-\mathrm{k}=64-29=32)$ dengan taraf signifikansi $\alpha=5 \%$ diperoleh nilai $\mathrm{F}_{\text {tabel }}=$ 1,84. Dilihat berdasarkan kriteria pengujian yang digunakan, maka diperoleh hasil pengujian hipotesis yang menunjukkan $F_{\text {hitung }}<\mathrm{F}_{\text {tabel }}$ maka $\mathrm{H}_{0}$ diterima sehingga dapat disimpulkan bahwa terdapat persamaan linier antara variabel efikasi diri dengan kesiapan kerja siswa.

\section{Uji Hipotesis}

Hubungan antara Pengalaman Praktik Kerja Industri dengan Kesiapan Kerja Siswa

Berikut adalah perhitungan uji hipotesis korelasi pearson product moment pengalaman praktik kerja industri dengan kesiapan kerja dapat dilihat pada tabel 7.

Tabel 7. Uji Korelasi Pearson Product Moment

\begin{tabular}{ccccc}
\hline $\mathbf{n}$ & $\alpha$ & $\begin{array}{c}\mathbf{r} \\
\text { hitung }\end{array}$ & $\begin{array}{c}\mathbf{r} \\
\text { tabel }\end{array}$ & Ket \\
\hline 64 & 0,05 & 0,644 & 0,246 & $\begin{array}{c}\mathrm{H}_{1} \\
\text { Diterima }\end{array}$ \\
\hline
\end{tabular}

\section{Hubungan antara Efikasi Diri dengan} Kesiapan Kerja Siswa

Berikut adalah perhitungan uji hipotesis korelasi pearson product moment efikasi diri dengan kesiapan kerja dapat dilihat pada tabel 8. Tabel 8. Uji Korelasi Pearson Product Moment

\begin{tabular}{ccccc}
\hline $\mathbf{n}$ & $\alpha$ & $\begin{array}{c}\mathbf{r} \\
\text { hitung }\end{array}$ & $\begin{array}{c}\mathbf{\text { Kabel }} \\
\text { tabet }\end{array}$ & Ker \\
\hline 64 & 0,05 & 0,572 & 0,246 & $\begin{array}{c}\mathrm{H}_{1} \\
\text { Diterima }\end{array}$ \\
\hline
\end{tabular}

Hubungan antara Pengalaman Praktik Kerja Industri dengan Efikasi Diri

Berikut adalah perhitungan uji hipotesis korelasi pearson product moment pengalaman praktik kerja industri dengan efikasi diri dapat dilihat pada tabel 9.

Tabel 9. Uji Korelasi Pearson Product Moment

\begin{tabular}{ccccc}
\hline \multirow{2}{*}{$\mathbf{n}$} & $\alpha$ & $\begin{array}{c}\mathbf{r} \\
\text { hitung }\end{array}$ & $\begin{array}{c}\mathbf{r} \\
\text { tabel }\end{array}$ & Ket \\
\hline 64 & 0,05 & 0,723 & 0,246 & На \\
\hline
\end{tabular}

Diterima

Hubungan antara Pengalaman Praktik Kerja Industri dan Efikasi Diri dengan Kesiapan Kerja Siswa

Berikut adalah perhitungan uji hipotesis korelasi pearson product moment pengalaman praktik kerja industri dan efikasi diri dengan kesiapan kerja siswa dapat dilihat pada tabel 10.

Tabel 10. Uji Korelasi Pearson Product Moment

\begin{tabular}{ccccc}
\hline \multicolumn{4}{c}{ Moment } \\
n & $\alpha$ & $\begin{array}{c}\text { r } \\
\text { hitung }\end{array}$ & $\begin{array}{c}\text { tabel } \\
\text { Ket }\end{array}$ \\
\hline 64 & 0,05 & 0,662 & 0,246 & $\begin{array}{c}\mathrm{H}_{1} \\
\text { Diterima }\end{array}$ \\
\hline
\end{tabular}

Uji Signifikansi

Pengalaman Praktik Kerja Industri dengan Kesiapan Kerja Siswa

Berikut adalah perhitungan uji signifikansi (uji-t) pengalaman praktik kerja industri dengan kesiapan kerja dapat dilihat pada tabel 11.

Tabel 11. Uji Signifikansi (Uji-t)

\begin{tabular}{ccccc}
\hline $\mathbf{d k}$ & $\alpha$ & $\begin{array}{c}\mathbf{t} \\
\text { hitung }\end{array}$ & $\begin{array}{c}\mathbf{t} \\
\text { tabel }\end{array}$ & Ket \\
\hline 62 & 0,05 & 6,628 & 1,998 & $\begin{array}{c}\mathrm{H}_{1} \\
\text { Diterima }\end{array}$ \\
\hline
\end{tabular}

\section{Efikasi Diri dengan Kesiapan Kerja} Siswa

Berikut adalah perhitungan uji signifikansi (uji-t) efikasi diri dengan kesiapan kerja dapat dilihat pada tabel 12.

\begin{tabular}{ccccc}
\multicolumn{4}{c}{ Tabel 12. Uji Signifikansi (Uji-t) } \\
\hline dk & $\alpha$ & $\begin{array}{c}\text { t } \\
\text { hitung }\end{array}$ & $\begin{array}{c}\text { t } \\
\text { tabel }\end{array}$ & Ket \\
\hline 62 & 0,05 & 5,490 & 1,998 & $\begin{array}{c}\mathrm{H}_{1} \\
\text { Diterima }\end{array}$ \\
\hline
\end{tabular}

\section{Pengalaman Praktik Kerja Industri dengan Efikasi Diri}

Berikut adalah perhitungan uji signifikansi (uji-t) pengalaman praktik kerja industri dengan efikasi diri dapat dilihat pada tabel 13. 


\begin{tabular}{ccccc}
\hline dk & $\alpha$ & $\begin{array}{c}\mathbf{t} \\
\text { hitung }\end{array}$ & $\begin{array}{c}\mathbf{t} \\
\text { tabel }\end{array}$ & Ket \\
\hline 62 & 0,05 & 8,240 & 1,998 & $\begin{array}{c}\mathrm{H}_{1} \\
\text { Diterima }\end{array}$
\end{tabular}

\section{Pengalaman Praktik Kerja Industri dan Efikasi Diri dengan Kesiapan Kerja Siswa}

Berikut adalah perhitungan uji signifikansi (uji-F) pengalaman praktik kerja industri dan efikasi diri dengan kesiapan kerja dapat dilihat pada tabel 14.

Tabel 14. Uji Signifikansi (UjiF)

\begin{tabular}{ccccc}
\multicolumn{6}{c}{$\mathbf{F})$} \\
dk & $\alpha$ & $\begin{array}{c}\text { F } \\
\text { hitung }\end{array}$ & $\begin{array}{c}\text { F } \\
\text { tabel }\end{array}$ & Ket \\
\hline 62 & 0,05 & 23,814 & 3,15 & $\begin{array}{c}\mathrm{H}_{1} \\
\text { Diterima }\end{array}$ \\
\hline
\end{tabular}

\section{KESIMPULAN DAN SARAN Kesimpulan}

Berdasarkan pembahasan yang telah diuraikan, maka diperoleh kesimpulan sebagai berikut:

1. Penelitian ini menyimpulkan bahwa terdapat hubungan yang positif dan signifikan antara pengalaman praktik kerja industri dengan kesiapan kerja siswa. Hal tersebut dibuktikan oleh nilai $r_{\text {hitung }}=0,644$ dengan $r_{\text {tabel }}=0,246$ dan nilai $t_{\text {hitung }}=6,628$ dengan nilai $t_{\text {tabel }}$ $=1,998$.

2. Penelitian ini menyimpulkan bahwa terdapat hubungan yang positif dan signifikan antara efikasi diri dengan kesiapan kerja siswa. Hal tersebut dibuktikan oleh nilai $r_{\text {hitung }}=0,572$ dengan $r_{\text {tabel }}=0,246$ dan nilai $t_{\text {hitung }}=5,491$ dengan nilai $t_{\text {tabel }}=1,998$.

3. Penelitian ini menyimpulkan bahwa terdapat hubungan yang positif dan signifikan antara pengalaman praktik kerja industri dengan efikasi diri. Hal tersebut dibuktikan oleh nilai $\mathrm{r}_{\text {hitung }}=0,723$ dengan $\mathrm{r}_{\text {tabel }}=0,246$ dimana $0,723>0,246$ dan nilai $t_{\text {hitung }}=8,240$ dengan nilai $t_{\text {tabel }}=1,998$.

4. Penelitian ini menyimpulkan bahwa terdapat hubungan yang positif dan signifikan antara pengalaman praktik kerja industri dan efikasi diri dengan kesiapan kerja siswa. Hal tersebut dibuktikan oleh nilai $\mathrm{r}_{\text {hitung }}=0,662$ dengan $r_{\text {tabel }}=0,246$ dan nilai $F_{\text {hitung }}=$ 23,814 dengan nilai $F_{\text {tabel }}=3,15$.

\section{Saran}

Berdasarkan kesimpulan yang didapat maka peneliti memiliki saran sebagai berikut:

1. Bagi Siswa

a. Siswa hendaknya dapat meningkatkan kemampuan literasi khususnya dibidang teknik instalasi listrik.

b. Siswa hendaknya berpartisipasi aktif saat mengikuti kegiatan praktik kerja industri dengan mengikuti SOP sesuai dengan prosedur.

c. Siswa hendaknya membuat buku konsultasi dan melakukan kegiatan konseling berkala sehingga mendapat solusi dari permasalahan tersebut.

d. Siswa hendaknya kerap mengikuti pelatihan-pelatihan yang dapat meningkatkan pengetahuan dan wawasan di bidang kejuruan.

2. Bagi Guru

a. Guru hendaknya lebih intensif dalam memberikan pembekalan konseling dan dukungan mengenai bimbingan karir khusunya untuk siswa kelas XII.

b. Guru hendaknya mengembangkan program pendidikan karir untuk semua siswa.

3. Bagi Sekolah

a. Sekolah hendaknya lebih intensif dalam memberikan fasilitas guna mendorong siswa lebih siap terjun ke dunia kerja nantinya.

b. Sekolah hendaknya mengembangkan pelatihan softskill kepada siswa untuk mendukung kesiapan kerja.

c. Sekolah hendaknya lebih memperhatikan manajemen praktik kerja industri dengan 
menyeleksi industri yang memiliki kredibilitas dan akuntabilitas.

d. Sekolah hendaknya menambahkan program kerja dalam memberikan konseling kepada siswa berupa informasi bimbingan karir sejak kelas X.

4. Bagi Industri Pasangan

a. Industri pasangan hendaknya lebih memperhatikan manajemen dalam pembagian tugas bagi siswa yang sedang melakukan kegiatan prakerin.

b. Industri pasangan hendaknya memberikan pendampingan serta monitoring siswa yang sedang melakukan kegiatan prakerin.

5. Bagi Peneliti Selanjutnya

Bagi peneliti selanjutnya yang tertarik untuk meneliti mengenai kesiapan kerja siswa, hendaknya mempertimbangkan untuk dapat melakukan penelitian dengan faktorfaktor lain selain efikasi diri dan pengalaman praktik kerja industri sehingga dapat mengetahui faktor apa yang paling memengaruhi tingkat kesiapan kerja siswa.

\section{DAFTAR PUSTAKA}

[1].Yudi Ganing Utami dan Hudaniah. 2013. Self Efficacy dengan Kesiapan Kerja Siswa Sekolah Menengah Kejuruan. Jurnal Universitas Muhammadyah Malang Vol. 01, No.01, Januari 2013. http://ejournal.umm.ac.id (Jurnal diakses 6 Juli 2019)

[2].Syafiq. 2013. Hubungan Kematangan Vokasional dan Efikasi Diri Terhadap Kesiapan Kerja Pada Siswa Kelas XII Program Keahlian Pemesinan SMK Negeri 3 Yogyakarta. Yogyakarta: Jurnal Pendidikan Universitas Negeri Yogyakarta.

[3].Sirsa, I Made, dkk. Kontribusi Ekspektasi Karier, Motivasi Kerja Dan Pengalaman Praktek Kerja Industri Terhadap Kesiapan Kerja Siswa Kelas
XII SMK Negeri 2 Seririt. Singaraja: Thesis Pendidikan Universitas Pendidikan Ganesha

[4].Dikmenjur. 2013. Pedoman Pelaksanaan Prakerin, Jakarta: Depdiknas.

[5].Sugiyono. 2012. Statistika Untuk Penelitian. Bandung: Alfabeta.

[6].Sugiyono. 2016. Metode Penelitian Kuantitatif Kualitatif dan $R \& D$. Bandung: Alfabet 